\title{
Electrical Impedance and Proton Conductivity Studies of Polymer Electrolyte Materials
}

\author{
K. Jeyabanu, P.Devendran, S. Asath Bahadur, N. Nallamuthu
}

\begin{abstract}
Solid electrolyte at different composition of 50\% $P V A+50 \% \mathrm{PVP}+x \% \mathrm{NaH}_{2} \mathrm{PO}_{2}$ are prepared using solution casting techniques. The prepared materials of polymer matrices are characterized through several techniques such as XRD, FTIR spectroscopy. The electrical conductivity of the sample is determined through measured impedance data at different frequencies and different temperatures. The electrical conductivity is calculated in the order of $10^{-8} \mathrm{Scm}^{-1}$. The water uptakencabability is also analysed. Proton conductivity is also analysed for vatious atmospheric condition.
\end{abstract}

Keywords- Solid electrolyte, PVA, PVP, protonic conductivity, Impedance

\section{INTRODUCTION}

Access to energy is key pillar and necessity in habitual life for poverty mitigation, human well being and economic development. However, our present available conventional energy systems have important environmental impacts. Historical and current energy systems are dominated by fossil fuels (coal, oil and gas) which produce carbon dioxide (CO2) and other greenhouse gases. If we are to meet avoid dangerous climate change, the world needs a significant transition to an environmental friendly energy sources. Among various environment friendly energy sources, solid state batteries (SSBs) have become one of the best energy sources with negligible pollutant.

For fabricating solid state batteries, solid electrolyte are much intensively analysed due to its more qualities than liquid electrolytes. The following rectification is essential to lead solid state batteries like time consuming in charge and discharge behavior, resulting in leakage and reaction with electrodes. Solid state batteries have high potential to make it as miniature with high energy density.Applications of SSBs include high energy-density storage/conversion devices such as lithium ion batteries, super capacitors, fuel cell, etc.[1].

Revised Manuscript Received on December 16, 2019

* Correspondence Author

N. Nallamuthu*, Department of Physics, Kalasalingam Academy of Research and Education, Krishnankoil - 626126. Tamil Nadu, India.

Email: n.nallamuthu@klu.ac.in

K. Jeyabanu, Department of Physics, Kalasalingam Academy of Research and Education, Krishnankoil - 626126.Tamil Nadu, India. Email: jeyabanu.gajendran@gmail.com

P. Devendran, Department of Physics, Kalasalingam Academy of Research and Education, Krishnankoil - 626126.Tamil Nadu, India. Email: pdevavenmani@gmail.com

S. Asath Bahadur, Department of Physics, Kalasalingam Academy of Research and Education, Krishnankoil - 626126.Tamil Nadu, India. Email: s_a_bahadur@yahoo.co.in
Solid-state battery technology is not only used for faster recharging for electric vehicles and consumer electronics but also grid energy storage, medical devices and avionics.[2].

Recent work on rechargeable, all-solid-state alkali-metal batteries has advanced the technology to a point where applications through the whole battery product range can be envisaged. Amongst the accessible battery chemistries, proton conducting rechargeable batteries have now captured much attention due to its environmentallyfriendly nature, non-toxic and moreover low cost and abundant materials and thus can be used in large or medium scale industries.[3].

In development of solid state batteries, the electrolyte has much important role by the reaction between the electrodes during the charge and discharge process occurring in solid state batteries.[4]. The superionic conductors are synthesized in different forms such as glass, polymer, crystalline and composites. Solid polymer electrolyte has more advantages and has more participation effect in miniaturization of devices. Due to its advantages like easy to prepare, light weight, flexible in shape and size, good mechanical strength. High energy density and good electrode and electrolyte contact solid electrolyte selected polycrystalline materials for several manufacturing devices.[5].

Poly vinyl alcohol (PVA) is a semicrystalline polymer studied extensively because of its many interesting physical properties which arise from the hydrogen bond formation due to the presence of $-\mathrm{OH}$ groups.[6-10]. Poly vinyl pyrrolidone(PVP) is a biopolymer with higher order of amorphosity, deserves a special attention among the conjugated polymers because of its good environmental stability, easy processability and moderate electrical conductivity.[11-14] The semicrystalline nature of PVA at room temperature, subsequently limits its ionic conductivity. One of the alternate way to enhance the amorphous nature of PVA based electrolyte systems is to blend with amorphous PVP polymer. The interactions between PVA and PVP is expected to occur through interhydrogen bonding between the carbonyl $(\mathrm{C}=\mathrm{O})$ group of PVP and the hydroxyl $(-\mathrm{OH})$ group of PVA.[15-19].

In the present study, PVA and PVP blended polymer doped with different concentrations of sodium dihydrogen Phosphate have been prepared by the solution casting method, and the polymer electrolytes have been subjected into composition and conductivity analysis.

Published By: 


\section{EXPERIMENTAL}

\section{A. Sample preparation}

Stoichiometric amount of polyvinylalcohol and polyvinyl pyrrolidone are dissolved by distilled water individually. Sodium hypo phosphate is also made as aqueous solution. Both polymer precursor solutions are mixed with continuous stirring to obtain transparent solution. Thus, Sodium hypo phosphate solution is also mixed with the previous transparent solution. The final solution is stirred constantly with maintain temperature $60 \mathrm{oC}$. The sol is become gel after dried it in oven. The dried film formed from gel was characterised by several methods.

\section{RESULTS AND DISCUSSION}

\section{A. X-ray diffraction (XRD) analysis}

The structural characteristics of pure 50PVA/50PVP blends with different $\mathrm{xwt} \%$ of $\mathrm{NaPO}_{2} \mathrm{H}_{2}[\mathrm{x}=1,2,3,4$ and $5 \%]$ were evaluated using $\mathrm{X}$-ray diffraction studies and were shown in Fig. 1. There is no such well defined peaks were observed for pure PVP, instead a broad hump was observed at the region of $2 \theta=10^{\circ}-20^{\circ}$, which can be associated with the amorphous nature of pure PVA-PVP. While adding the salt in the blend polymer, four different humps are obtained. The relative intensity of the broad hump decreases by increasing the concentration of $\mathrm{NaPO}_{2} \mathrm{H}_{2}$. The intensity of broad hump in peaks corresponding to $\mathrm{NaPO}_{2} \mathrm{H}_{2}$ arenot found to be present in the Polymer blend electrolytes which indicate the complete dissolution of the salt in the polymer blend upto the concentration of $5 \mathrm{wt} \%$ of $\mathrm{NaPO}_{2} \mathrm{H}_{2}$. The amorphous nature results in high ionic conductivity of the polymer blend electrolyte.[20].

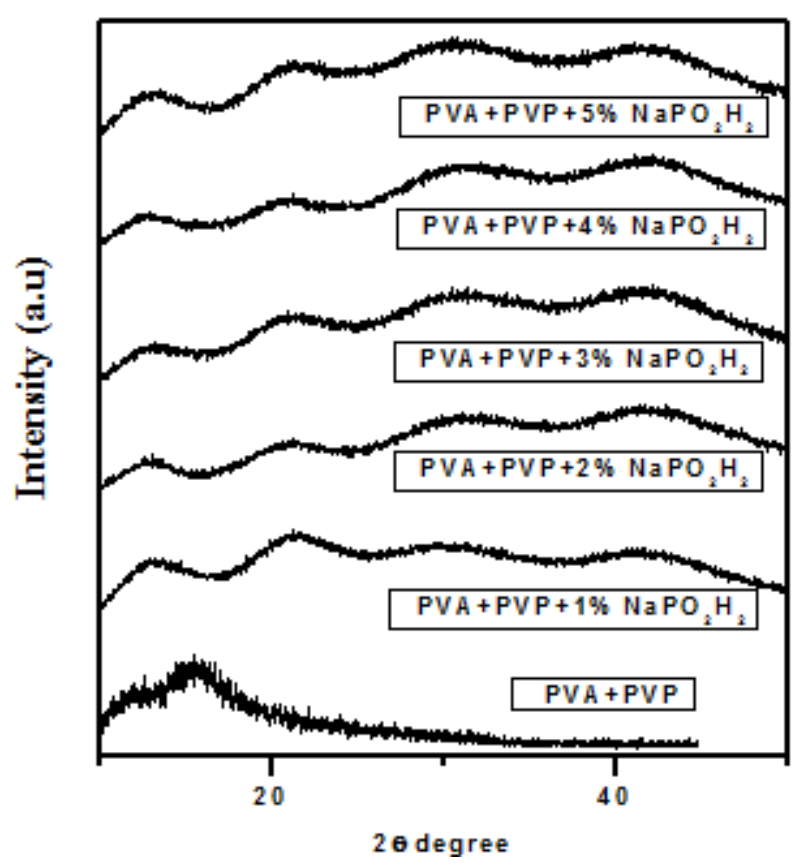

Fig.1. XRD pattern for $\mathrm{NaPO}_{2} \mathrm{H}_{2}$ mixed PVA+ PVP polymer sample. XRD pattern is low for PVA+PVP $+3 \%$ of $\mathrm{NaPO}_{2} \mathrm{H}_{2}$. XRD

\section{B. Water uptake measurement}

protonic conductivity performance of the materials are enhanced depends on the existing water molecule and water uptaken in the sample. The mechanical properties of the polymer film is also obtained due to water up taken capability of the sample. Water uptake measurement or gravimetric technique are performed to determine the swelling properties of the polymer where the 50PVA/50PVP doped with $\mathrm{x}$ wt $\%$ of $\mathrm{NaPO}_{2} \mathrm{H}_{2}$ blends were immersed in water at room temperature. The following formula is determined

Water uptake $=$ Wwet-Wdry/Wdry* $100 \%$

where $w_{\text {dry }}$ is the mass of the dried sample before the measurement and $\mathrm{w}_{\mathrm{wet}}$ the mass of the wet sample.

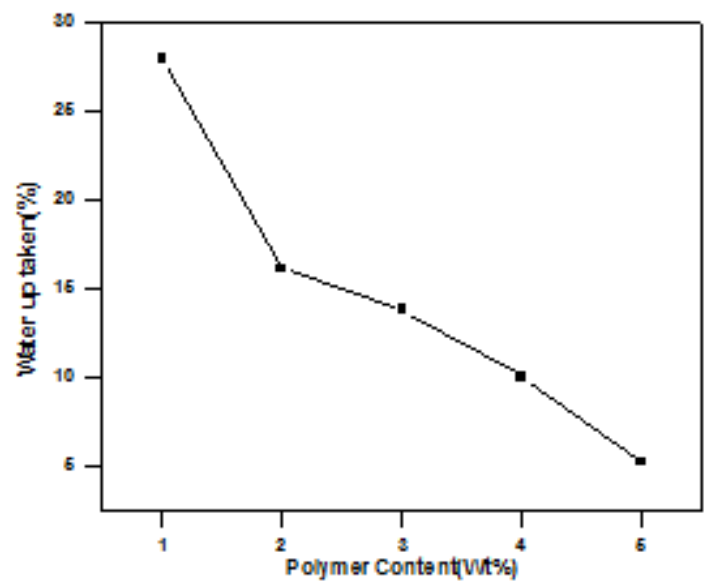

Fig.2. Water uptake measurement for various composition of blend polymer films.

Fig. 2. is displayed the water uptaken values for all the composition of PVA-PVP mixed sodium hypo phosphate samples. $1 \% \mathrm{NaH}_{2} \mathrm{PO}_{2}$ is having more water uptaken values and it is decreased for increasing salt concentration in polymer matrices [21].

\section{Ion Exchange capacity}

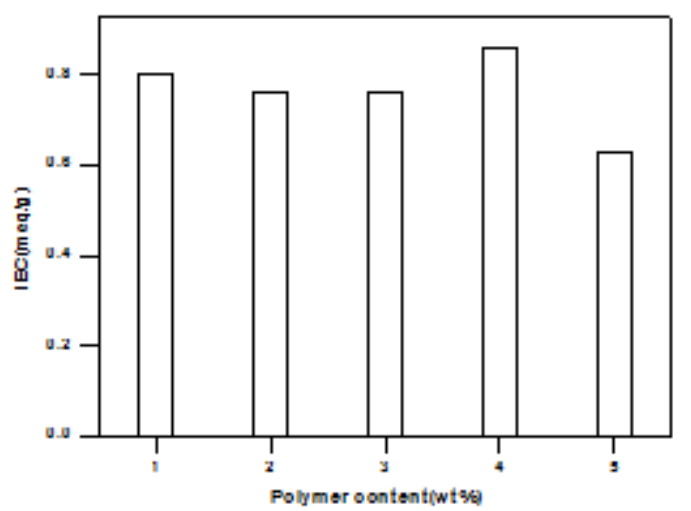

Fig.3. Ion exchange capacity for $\mathrm{NaPO}_{2} \mathrm{H}_{2}$ mixed PVA+ PVP polymer sample.

Ion exchange capacity is measured by back titration. At first, sample is washed by distilled water to remove any impurities observed on the surface of polymer film. The resulted polymer is immersed in $0.01 \mathrm{M} \mathrm{HCl}$ and then it titrated by $\mathrm{NaOH}$ solution. Here Phenolpthelein is used as indicator [22]. The Ion

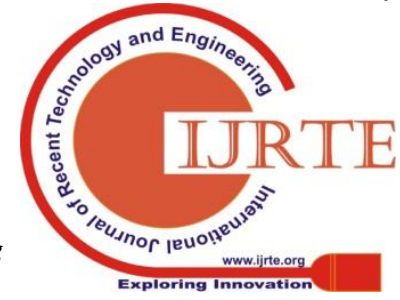


membrane capacity is slightly high for 4\% Sodium Hypo Phosphate +PVA -PVP polymer matrices.

\section{Protonic Conductivity}

Protonic conductivity is calculated from measured impedance of sample at different frequencies at different atmosphere. The sample of $1 \%$ provide higher protonic conductivity for $100 \% \mathrm{R}_{\mathrm{H}}$. While increasing the concentration, the proton conductivity is decreased. At $4 \%$ polymer, it has also showed the better conductivity. At the lower composition, the protonic conductivity is obtained due to the existing $\mathrm{OH}$ molecules and obtained pore molecules. The proton movement is also increased with increasing ICE and water uptaken values. At higher composition, the conductivity is obtained due to the increasing water molecules in polymer films [23].

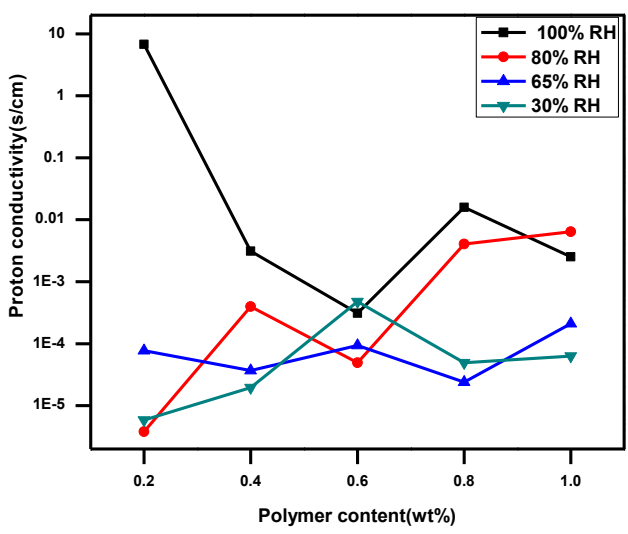

Fig. 4. Protonic conductivity of all the composition of polymer matrices

\section{CONCLUSION}

PVA and PVP mixed soldium hypo phosphate at different compositions were prepared by solution- casting method. The prepared samples are showed the amorphous nature for blend polymer and all the various composition of Sodium hypophasphate salt mixed blend polymer. The amorphous nature enhance the ionic conductivity for polymer sample. Protonic conductivity, waterup taken measurement and Ion exchange capacity are also analysed for all the blend polymer sample. The protonic conductivity is higher for $4 \mathrm{wt} \%$ of sodium hypo phosphate mixed sample than other all composition.

\section{ACKNOWLEDGMENT}

Author K.Jeyabanu and NNM thanks management of kalasalingam academy of research and education for providing the URF.

\section{REFERENCES}

1. A. Bozkurt "Application of proton conducting polymer electrolytes to electrochromic devices." Turkish Journal of Chemistry, vol. 26.5 (2002) pp. 663-668.

2. Lewandowski, A., M. Zajder, E. Frąckowiak, and F. Beguin "Supercapacitor based on activated carbon and polyethylene oxide- $\mathrm{KOH}-\mathrm{H} 2 \mathrm{O}$ polymer electrolyte." Electrochimica Acta, vol. 46.18 (2001) pp. 2777-2780.

3. Chen, Ningping, and Liang Hong. "Proton-conducting membrane composed of sulfonated polystyrene microspheres, poly (vinylpyrrolidone) and poly (vinylidene fluoride)." Solid State Ionics vol. 146.3-4 (2002) pp. 377-385..

4. Duraikkan, Vanitha, Asath Bahadur Sultan, Nallamuthu Nallaperumal, and Athimoolam Shunmuganarayanan "Structural, thermal and electrical properties of polyvinyl alcohol/poly (vinyl pyrrolidone)-sodium nitrate solid polymer blend electrolyte." Ionics vol. 24.1 (2018) pp. 139-151.

5. De Silva, D. Awanthi, Buddhika U. Hettiarachchi, L. D. C. Nayanajith, MD Yoga Milani, and J. T. S. Motha "Development of a $\mathrm{PVP} /$ kappa-carrageenan/PEG hydrogel dressing for wound healing applications in Sri Lanka." Journal of the National Science Foundation of Sri Lanka vol. 39.1 (2011) pp. 25-33.

6. Vincent, Colin A "Polymer electrolytes." Progress in solid state chemistry vol. 17.3 (1987) pp. 145-261.

7. Vargas, M. A., R. A. Vargas, and B. E. Mellander. "New proton conducting membranes based on PVAL/H3PO2/H2O." Electrochimica Acta vol. 44.24 (1999) pp. 4227-4232..

8. Vargas, R. A., V. H. Zapata, E. Matallana, and M. A. Vargas "More thermal studies on the $\mathrm{PVOH} / \mathrm{H} 3 \mathrm{PO} 2 / \mathrm{H} 2 \mathrm{O}$ solid proton conductor gels." Electrochimica Acta vol. 46.10-11 (2001) pp. 1699-1702..

9. Vargas, M. A., R. A. Vargas, and B-E. Mellander. "Phase Behavior of a PVAL-Based Polymer Proton Conductor." physica status solidi (b) vol. 220.1 (2000) pp. 615-624.

10. Feng, Hanqiao, Zhiliu Feng, and Lianfang Shen. "A high resolution solid-state nmr and dsc study of miscibility and crystallization behaviour of poly (vinyl alcohol) poly (N-vinyl-2-pyrrolidone) blends." Polymer vol. 34.12 (1993) pp. 2516-2519)

11. Zieba, Jaroslaw W., Yue Zhang, Paras N. Prasad, Martin K. Casstevens, and Ryszard Burzynski. "Sol-gel-processed inorganic oxides: organic polymer composites for second-order nonlinear optical applications." In Sol-Gel Optics II, vol. 1758, (1992) pp. 403-409. International Society for Optics and Photonics.

12. Reddy, Ch V. Subba, A. K. Sharma, and VVR Narasimha Rao. "Electrical and optical properties of a polyblend electrolyte." Polymer vol. 47.4 (2006) pp. 1318-1323..

13. Reddy, Ch V. Subba, Ai-Ping Jin, Xia Han, Quan-Yao Zhu, Li-Qiang Mai, and Wen Chen "Preparation and characterization of (PVP+ V2O5) cathode for battery applications." Electrochemistry communications vol. 8.2 (2006) pp. 279-283.

14. Rajeswari, N., S. Selvasekarapandian, S. Karthikeyan, C. Sanjeeviraja, Y. Iwai, and J. Kawamura. "Structural, vibrational, thermal, and electrical properties of PVA/PVP biodegradable polymer blend electrolyte with CH 3 COONH 4." Ionics vol. 19.8 (2013) pp. 1105-1113.

15. Hatta, F. F., M. Z. A. Yahya, A. M. M. Ali, R. H. Y. Subban, M. K. Harun, and A. A. Mohamad. "Electrical conductivity studies on PVA/PVP-KOH alkaline solid polymer blend electrolyte." Ionics vol. 11.5-6 (2005) pp. 418-422.

16. Polu, Anji Reddy, and Ranveer Kumar. "Ionic conductivity and discharge characteristic studies of PVA-Mg (CH3COO) 2 solid polymer electrolytes." International Journal of Polymeric Materials vol. 62.2 (2013) pp. 76-80.

17. Polu, Anji Reddy, and Ranveer Kumar. "Preparation and characterization of PVA based solid polymer electrolytes for electrochemical cell applications." Chinese Journal of Polymer Science vol. 31.4 (2013) pp. 641-648.

18. Polu, Anji Reddy, Ranveer Kumar, K. Vijaya Kumar, and N. Krishna Jyothi. "Effect of $\mathrm{TiO}_{2}$ ceramic filler on PEG-based composite polymer electrolytes for magnesium batteries." In AIP Conference Proceedings, vol. 1512 (2013) pp. 996-997.

19. Polu, Anji Reddy, and Ranveer Kumar. "AC impedance and dielectric spectroscopic studies of $\mathrm{Mg} \mathrm{2+}$ ion conducting PVA-PEG blended polymer electrolytes." Bulletin of Materials Science vol. 34.5 (2011) pp. 1063-1067.

20. Park J.S., Park J.W. and Ruckenstein E., Thermal and Dynamic Mechanical Analysis of PVA/MC Blend Hydrogels, Polymer, vol. 42(9), (2001) pp. 4271-4280.

21. Peighambardoust, S. Jamai, Soosan Rowshanzamir, and Mehdi Amjadi "Review of the proton exchange membranes for fuel cell applications." International journal of hydrogen energy vol. 35.17 (2010) pp. 9349-9384. 
22. Fernandez FJ, Compan V, Riande E. Hybrid ion-exchange membranes for fuel cell and separation processes. J Power Sourc vol. 173 (2007) pp. 68-76.

23. Chen, Ningping, and Liang Hong. "Proton-conducting membrane composed of sulfonated polystyrene microspheres, poly (vinylpyrrolidone) and poly (vinylidene fluoride)." Solid State Ionics vol. 146.3-4 (2002) pp. 377-385.

\section{AUTHORS PROFILE}

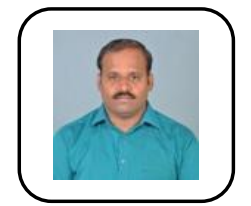

Dr. N. Nallamuthu has obtained his M.Phil. and Ph.D. physics in Pondicherry University, puducherry. Since 2012, he is working as an Associate Professor in Department of Physics, Kalasalingam Academy of Research and Education, Virudhunagar. His area of research mainly focused on solid state ionics, $\sim 20$ research articles in reputed international journals. nanomaterials based energy devices. He has published

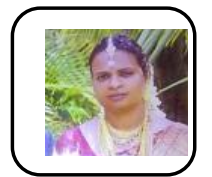

K. Jeya Banu is a Research scholar in the department of Physics, International Research Centre (IRC) Kalasalingam Academy of Research and Education, India. She is research in the area of Polymer Science.

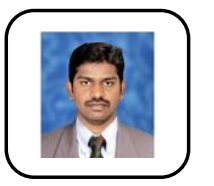

Dr. P. Devendran received his Ph.D degree in Physics from Madras University at Chennai in 2016, developing metal oxides and metal sulfide nano-catalysts for photocatalytic application. After he moved for postdoctoral studies at IRC, Kalasalingam academy of Research and education, he becomes an Assistant Professor of Physics at the same institution and presently began studying metal oxide modified graphene based materials for energy storage device application and their surface science. He published more than 28 research articles and book chapters in reputed journals.

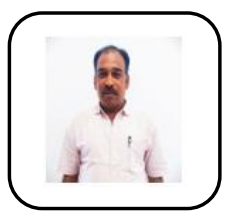

Dr. S. Asath Bahadur Is A Senior Professor In The Department Of Physics, School Of Advanced Sciences At Kalasalingam Academy Of Research And Education, India. He Has Obtained Ph.D. In The Area Of X-Ray Crystallography From Madurai Kamaraj University In 1994 And Also Received His M.Phil. And M.Sc. Degree In Physics From Madurai Kamaraj University.He Has Expertise In The Areas Of Crystallography And Material Science. He Has Published More Than Eighty-Fivepeer-Review Research Articles In Journals Of International Repute Besides Seventy More As Proceedings. 